\title{
EL DEBATE CHINO-SOVIÉTICO Y LA EMERGENCIA DEL MAOÍSMO COMO CORRIENTE POLÍTICA DIFERENCIADA EN EL MOVIMIENTO COMUNISTA INTERNACIONAL
}

\section{THE SINO-SOVIET SPLIT AND THE EMERGENCE OF MAOISM AS A DIFFERENT BRANCH INTO THE INTERNATIONAL COMMUNIST MOVEMENT}

\author{
Brenda Rupar \\ CONICET-Argentina
}

ORCID: https://orcid.org/0000-0001-7630-4068

Recibido el 25-7-2017 y aceptado el 5-12-2017

Resumen: En octubre de 1949 y después de largas décadas de lucha, el pueblo chino liderado por el Partido Comunista Chino consiguió el triunfo que abrió paso a la revolución de Nueva Democracia y al socialismo. Mao Tse Tung era el principal dirigente de aquel Partido en el momento de la toma del poder.

Con el correr de los años la revolución fue ganando la simpatía de otros países del Tercer Mundo. No obstante, el maoísmo sólo emergió como corriente diferenciada dentro del Movimiento Comunista Internacional en la década de 1960 y como consecuencia de varios años de enfrentamiento con el Partido Comunista de la Unión Soviética, que lideraba el bloque socialista en el contexto de la Guerra Fría.

Frente a la rápida asimilación que suele haber entre la Revolución China y el maoísmo, el presente trabajo propone una interpretación que, sin dejar de reconocer que se trata de aspectos íntimamente vinculados, se propone especificar y explicar el momento de la emergencia del maoísmo como corriente política diferenciada dentro del Movimiento Comunista Internacional.

Trabajaremos con los documentos del «debate chino-soviético» y las Conferencias Mundiales de 1957 y 1960, ofreciendo un análisis y periodización como propuesta para su estudio. 
Palabras clave: Revolución China, Maoísmo, «Debate chino-soviético», Movimiento Comunista Internacional.

Abstract: In October 1949, and after decades, the Chinese Revolution triumphed. Mao Tse Tung was the main leader of the Chinese Communist Party at that time.

The Revolution caused sympathy and admiration in Third World countries. However, it was only in the sixties when Maoism appeared as a different branch into the International Communist Movement. It was due to a confrontation against the Communist Party of the Soviet Union, which led the socialist world in the context of the Cold War.

It is usual to mix up Chinese Revolution and Maoism, as if they were the same. Even we recognize that they are part of a same process, in this article we propose a way to explain the specific emergence of Maoism as a different international movement.

We work with the documents of the split, and the 1957 and 1960 World Conferences, offering an analysis and periodization.

Keywords: Chinese Revolution, Maoism, Sino-soviet split- International Communist Movement. 


\section{Introducción}

La Revolución China fue la primera revolución socialista triunfante en un país oprimido y 1949 fue el final de un largo proceso de una guerra de liberación que había comenzado en 1911, cuando el régimen de gobierno aún era monárquico. Una guerra de guerrillas del campo a la ciudad, que fue liberando zonas y colocándolas bajo el control del PCCh y de los habitantes locales, acentuando una situación de doble poder.

Las simpatías con la Revolución China comenzaron tempranamente y su influencia hasta los años sesenta se sintió principalmente en el continente asiático, no sólo por la cercanía geográfica, sino también por la ayuda material de los chinos a otros procesos revolucionarios, como el de Corea. También sedujo a personas y organizaciones de países oprimidos con características similares a China.

A partir de los años sesenta, la aparición de partidos que se reconocían maoístas y otras expresiones que reclamaban su influencia, dieron cuenta de la existencia de un fenómeno que adquiría rasgos particulares y que era preciso caracterizar.

A grandes rasgos, hubo dos grandes momentos en que fueron valorados y discutidos los aportes o contribuciones que habría legado el maoísmo: uno en los años 60 y 70 y otro más actual. En aquel entonces, para algunos, la contribución del maoísmo consistía apenas en novedades en la táctica y la estrategia revolucionarias que inclusive sólo se reducían al caso chino. Asimismo, se le cuestionaban un fuerte rasgo idealista. Esa perspectiva es, por ejemplo, la que se sostenía en la URSS en la década de $1960^{1}$ y la de los intelectuales críticos de la experiencia china. Adicionalmente criticaban la intención, según ellos entendían, del Partido Comunista Chino (PCCh) de extender esas conclusiones a todos los países de Asia, África y América Latina. Por el contrario, para quienes se reconocen maoístas, el mismo era considerado un tercer momento en el desarrollo histórico de la teoría marxista-leninista ${ }^{2}$. Gran parte de esta producción se dio centralmente en Europa y EE.UU. En América Latina, las valoraciones nacían más vinculadas a diferentes grupos de militancia.

En los últimos veinte años, el maoísmo ha recobrado cierta atención en el campo académico, con obras que han legado nuevas perspectivas

\footnotetext{
1 AAVV, 1972.

2 Toledo Bruckmann, 2015.
} 
conceptuales al fenómeno. En general, predominan los estudios parciales sobre el maoísmo en determinados países. ${ }^{3}$ Sin embargo, una interpretación recientemente publicada y que da cuenta de un conjunto más amplio de fenómenos, sostiene que

«hay seis características que diferencian el maoísmo de otras corrientes marxistas: 1) el trabajo de masas en el mundo rural encaminado a la creación de un doble poder (las bases de apoyo); 2) la búsqueda de un gran frente político que agrupe a la mayoría de la población, incluida la burguesía nacional; 3) el modelo de la Guerra Popular Prolongada (GPP) que privilegia el escenario campesino; 4) la consideración de la que la URSS era una potencia socialimperialista y los miembros del Partido Comunista (PC), revisionistas, es decir, contrarios a la revolución; 5) la reivindicación de una etapa intermedia sin colectivización ni estatización, la Nueva Democracia; y 6) la existencia de un principio moral con el que deben trabajar los militantes: estar al servicio del pueblo». ${ }^{4}$

En esta definición aparecen condensados diferentes elementos que abordaremos de inmediato.

Existen diferentes posiciones al respecto de cuándo es posible hablar de «maoísmo»: si con el triunfo de la Revolución en 1949 y la influencia a otros países que tomaron algunos rasgos de aquella experiencia, o si sólo a partir de 1960. El recorrido de nuestro trabajo procurará enmarcar al maoísmo como una corriente diferenciada al interior del Movimiento Comunista Internacional que emergió en la década de 1960. Se trata de un análisis de fuentes, a través de las cuales abordaremos los fundamentos de su desarrollo y rastraremos sus antecedentes.

Siendo que en América Latina el campo de estudios acerca del maoísmo es relativamente reciente y que aún es preciso establecer algunas líneas que orienten en la pesquisa, en este trabajo proponemos una reconstrucción de diferentes elementos y momentos que nos ayuden a definir con mayor precisión el uso del término.

3 A modo de ejemplo, y sin pretender agotar la producción que se ha venido realizado, referimos a los trabajos de Rothwell, 2013; Cardina, 2011; Archila, 2008, Rodrigues Sales, 2000 .

${ }^{4}$ Urrego, 2017, pp 111-135. Para una problematización de algunas de las interpretaciones acerca del maoísmo, remitimos a nuestro trabajo Rupar, 2017a. 


\section{Dos aspectos y dos momentos}

En este trabajo proponemos que hasta $1972^{5}$ se pueden identificar dos aspectos de los llamados «aportes» de la Revolución China al marxismoleninismo y dos momentos en los cuales ganaron reconocimiento en las izquierdas del mundo: el primer elemento estaría compuesto por las particularidades del programa y del camino de la revolución, principalmente la experiencia de la guerrilla rural y del Frente Único Anti-imperialista (vinculado al hecho de ser la primera revolución triunfante en un país semifeudal y semicolonial y que, debido a eso, la revolución no habría sido socialista de inicio, sino que contó con una etapa democrático-popular). El segundo aspecto tendría que ver con la elaboración de la teoría de la continuidad de la lucha de clases en el socialismo (vinculado al análisis sobre la URSS) y el período de la Revolución Cultural Proletaria. ${ }^{6}$ Dichos aspectos no se eliminaron, sino que se fueron condicionando. ¿Todos ellos forman parte del «maoísmo»? A esta pregunta podría responderse tanto afirmativa como negativamente sin temor a equivocarse. Es decir, los dos aspectos fueron ciertamente inspiradores para otras organizaciones. Sin embargo, entendemos que no tienen la misma jerarquía y que, de hecho, fue uno el segundo de ellos el que hizo del maoísmo una corriente diferenciada (o «continuadora», como ellos se autodenominan) del marxismoleninismo. Los analizaremos a continuación.

\section{Sobre la revolución de Nueva Democracia, el frente único y la dirección} del proceso revolucionario

Tras el triunfo de la revolución, en octubre de 1949, las primeras características que llamaron la atención fueron el camino revolucionario del campo a las ciudades y la organización del ejército con base campesina. Esas particularidades impactaron sobre todo en países con gran presencia campesina y con fuerte base agraria, porque aparecían como una respuesta

5 En 1972 acontecieron dos hechos que dividieron al maoísmo: los acuerdos con los EUA, simbolizada por la visita del presidente Richard Nixon a China, y la muerte del dirigente Lin Piao en un accidente aéreo. En este trabajo no vamos a abordarlos.

${ }^{6}$ Existen efectivamente otros elementos como por ejemplo, el estilo de trabajo, pero creemos que no fueron determinantes, aunque sí influenciaron e inspiraron a diferentes personalidades y organizaciones. 
a las dificultades de organizar a la población urbana. A pesar de que haya sido lo que primero que llamó la atención, recién a mediados de la década de 1950 se tornó una especie de «modelo» con amplia difusión, en el momento en el que el Tercer Mundo ganaba identidad en los procesos de liberación nacional y social que transcurrían en Asia, África y América Latina. China participaba desde 1955 en el Grupo de Países No Alineados, con una notable y creciente influencia en las conducciones de los países asiáticos y africanos.

Otro elemento vinculado a aquél, y que fue ganando cada vez mayor presencia, fue el análisis de la estructura de clases, de las formaciones económico-sociales (FES) en los países oprimidos (especialmente en los semicoloniales y en los coloniales) y, consecuentemente, del Frente Único revolucionario. La III Internacional de filiación comunista ya había teorizado sobre la Cuestión Nacional y, consecuentemente, sobre las revoluciones en los países coloniales y semicoloniales. Pero la práctica política de varios de los Partidos Comunistas del mundo acabó en el llamado seguidismo de las burguesías nacionales o siendo traicionadas por esa clase, llevando a la derrota a muchas de las experiencias (inclusive en China, en el período 1925-1927).

En China, la formulación sobre el tipo de revolución fue hecha incluyendo una nueva perspectiva. Mao había caracterizado el tipo de revolución como de Nueva Democracia. Aún se mantenían las dos etapas (la revolución democrática y la socialista) y sostenían que eran «cualitativamente diferentes» y que sólo se podía pasar a la segunda una vez terminada la primera ${ }^{7}$. Sobre aquélla, señalaba que:

En lo político, se propone implantar la dictadura conjunta de las diversas clases revolucionarias contra los imperialistas, los colaboracionistas y los reaccionarios, y se opone a la transformación de la sociedad china en una sociedad de dictadura burguesa. En lo económico, tiene como propósito nacionalizar el gran capital y las grandes empresas de los imperialistas, los colaboracionistas y los reaccionarios, y distribuir la tierra de la clase terrateniente entre los campesinos; junto con ello, conservará las empresas capitalistas privadas en general y no eliminará la economía de campesino rico. Así, esta revolución democrática de nuevo tipo, aunque por un lado desbroza el camino para el capitalismo, por el otro crea las premisas para el so-

7 Mao Tse Tung, 1940, p 356; Mao Tse Tung, 1939. 
cialismo. La presente etapa de la revolución china es una etapa de transición cuyo objetivo consiste en poner fin a la sociedad colonial, semicolonial y semifeudal y preparar las condiciones para la edificación de la sociedad socialista, o sea, es el proceso de una revolución de nueva democracia. ${ }^{8}$

En el texto puede leerse que la primera etapa de la revolución no proponía como objetivo el desarrollo capitalista de los países «atrasados», lo que podría conducir a colocar a la burguesía como una clase revolucionaria. ${ }^{9}$ De la caracterización del tipo de revolución se pasaba a la identificación de cuáles eran las «clases revolucionarias». Dentro del Frente Único Revolucionario, Mao Tse Tung y el PCCh habían dividido a las clases y sectores sociales en fuerzas motrices y fuerza directriz. Eso aisladamente no aporta ninguna novedad, ya que significaba nombrar o teorizar sobre un hecho del proceso revolucionario (lo meritorio, de cualquier modo, era hacerlo anticipadamente). En particular, nos interesa que hacía una diferenciación en las burguesías de los países oprimidos, por un lado, en burguesía compradora (en alianza subordinada con el imperialismo) y, por otro, la burguesía nacional (con un carácter dual, porque por un lado explota trabajo ajeno pero, al mismo tiempo, vería limitada su reproducción por la presencia imperialista) ${ }^{10}$. La diferenciación iba de la mano con una táctica diferenciada para cada una. Tomando todo esto en consideración, en este primer momento los aspectos de mayor difusión fueron «el camino», junto con la organización de la Guerra Popular Prolongada en los países con mayoría campesina.

En el caso de la Revolución de Nueva Democracia y el análisis de las clases sociales, a pesar de ser formulaciones del primer período, no impactaron (por lo menos en América Latina) hasta unos años después y como consecuencia de la aproximación al maoísmo en la década de 1960.

Se podría decir que hasta este momento, China y la Revolución China aparecían como una particularidad dentro del marxismo-leninismo y de un MCI unificado bajo la dirección de la URSS.

8 Mao Tse Tung, 1939

${ }^{9}$ En el contexto mundial y la crisis que atravesaban los PCs en los países del Tercer Mundo, la formulación representaba una novedad para problematizar el tratamiento a las burguesías nacionales.

10 Mao Tse Tung, 1939 
Sobre la continuidad de la lucha de clases en el socialismo y la Revolución Cultural Proletaria

Si, como sostuvimos, hasta la década de 1960 era difícil hablar de «maoísmo», podemos decir que por el contrario, a partir de ese momento la corriente ganó identidad. Evidentemente, todos los aspectos están vinculados a un aspecto real, existente, de la Revolución China y su impacto. Tomar una posición respecto de la fecha está muy vinculado a cuáles se consideran las novedades y los aportes que incorporaron las organizaciones. De 1949 hasta 1956, la influencia fue a partir del ejemplo de una revolución triunfante por otro camino y con otras características (país oprimido, mayoría campesina, del campo a las ciudades, a través de una Guerra Popular Prolongada, tratamiento de las burguesías nacionales en el Frente Único Revolucionario). A partir de entonces, las simpatías fueron cada vez más en paralelo con el desarrollo del debate chino-soviético que sólo a partir de 1960 quedó más explícito, cuando la URSS retiró todos los técnicos soviéticos que estaban en China. En ese período, varios partidos y organizaciones se inclinaron por los postulados chinos, reivindicando al marxismo-leninismo en contra del PCUS que, según las acusaciones hechas por el PCCh, lo estaría revisando.

De cualquier modo, el gran cambio se presentó cuando Mao Tse Tung dio un salto en la caracterización y acusó que en la URSS había sido restaurado el capitalismo y que esta se había tornado «social-imperialista». Por esta razón, 1963 (año de la ruptura de las relaciones entre el PCCh y el PCUS) aparece como clave en esta cronología. Quienes como nosotros concuerdan con la posibilidad de hablar de «maoísmo» sólo a partir de entonces, el eje estaría colocado principalmente en la elaboración de la teoría de la continuidad de la lucha de clases aun en el socialismo. La consecuencia práctica de esto en China habría sido el impulso de la Revolución Cultural Proletaria desde $1966^{11}$.

Si ya el debate con la URSS había conmovido las estructuras partidarias de la izquierda, el hecho de que la Revolución Cultural estuviese di-

11 Tal etapa (1966-76) se caracterizó por un enfrentamiento directo con aquellos que expresarían (consciente o inconscientemente) el camino «restaurador del capitalismo» en China, en contra de quienes por el contrario, estarán a la búsqueda de profundizar las reformas y el «camino al comunismo». La lucha se manifestó en amplios y profundos debates ideológicos sobre prácticas y formas de vida que movilizaron a toda la población. 
rigida en contra de un sector del propio Comité Central del PCCh, conmovió aún más las costumbres de aquel mundo. Como sostuvimos en otro trabajo, frente a las críticas a la URSS de aquella época por su burocratización o degeneración o economicismo, el maoísmo ofrecía un análisis en el que «el problema no era el socialismo en abstracto, el problema era lo que estaba pasando en la URSS y que estaba vinculado a la restauración del capitalismo allí. Podrían cuestionarlo, criticarlo y hasta oponerse sin renegar del marxismo-leninismo. Bien por el contrario, refugiándose en él.» ${ }^{12}$

El análisis que Mao hizo sobre la Unión Soviética, para algunos ayudaba en el desarrollo de la teoría (ya Lenin y Stalin se habrían preocupado con la posibilidad de restauración) y daba herramientas para sustentar y construir el socialismo, mientras que para otros significaba una acusación fuertísima, responsable por la crisis que sobrevino en el Movimiento Comunista Internacional (MCI).

Por eso, a partir de este momento, la adopción explícita del maoísmo suponía el cuestionamiento al PCUS y a la URSS, sobre todo desde el XX Congreso en 1956. Después de la ruptura, reconocerse maoísta tenía una carga políticamente más fuerte; y nadie se reconocía abiertamente maoísta si no concordaba con los postulados chinos en el debate. ${ }^{13}$ Queremos aclarar que a pesar de estas posiciones, no consideramos al maoísmo como una entidad sin cambios a los largo de este período. Por el contrario, tuvo varios momentos y rupturas. Sin embargo, para los objetivos de este trabajo y debido al período estudiado, optamos por concentrarnos en las características señaladas.

Por ese motivo es que centramos nuestro trabajo en el período 19561963, tomando como fechas límites el XX Congreso del PCUS y la definitiva ruptura de relaciones entre China y la URSS. En términos de organización de nuestra exposición, empezaremos por el final, cuando se publican los documentos y se hace explícito el debate. A partir de esto y sosteniendo que hubo un período en el que se gestó la división inclusive estando el MCI unificado, pasaremos a analizar lo que consideramos dos momentos clave de ese proceso.

12 Rupar, 2017.b., pp. 370-371.

${ }^{13}$ Fue, por ejemplo, el caso del partido boliviano, que no fue reconocido oficialmente hasta 1966/1967, porque no quedaba claro su apoyo a los chinos en el debate Alexander, 1999, pp. 56-57. 


\section{El «Debate chino-soviético»}

Si afirmamos que el «maoísmo», en tanto corriente teórico-política dentro del marxismo, sólo comenzó a delinearse a partir de ese debate, entonces es preciso analizarlo.

Esa discusión (luego llamado «debate o conflicto chino-soviético»), que oponía diferentes concepciones de la situación mundial y sobre lo que debía ser hecho y cómo, llevó a la ruptura de los vínculos entre el PCUS y el PCCh. A pesar de las tentativas de mantener las diferencias en secreto mientras se desarrollaba el intercambio, varias razones contribuyeron para que se conociera en todo el mundo, por lo que atravesó la política internacional del período y mucho más a las organizaciones de la izquierda. ${ }^{14}$ Para abordarlo y entender lo que era debatido, utilizaremos las publicaciones, cartas y respuestas que hicieron circular tanto el PCUS como el PCCh en medio de las controversias (1956-1963).

Si tomamos a las fuentes en su conjunto, podemos agrupar los puntos del debate en los siguientes ejes (que, a pesar de que los separemos por cuestiones analíticas, están íntimamente relacionados): acerca del culto a la personalidad, los debates sobre la posibilidad de coexistencia pacífica entre los bloques socialista y capitalista, la vía para la revolución (violenta o pacífica), y sobre la posibilidad de llamar «Estado de todo el pueblo» al Estado socialista. Si bien los debates también abordaron el análisis y la caracterización de países como Albania y Yugoslavia, sostenemos que en realidad inicialmente se utilizaban las referencias a dichos países como forma de eludir una confrontación directa entre ellos. A medida que avanzaba, quedó claro que a través de las críticas a Yugoslavia el PCCh buscaba atacar a la URSS, quien respondía descalificando la experiencia albanesa, aliada a China.

\section{a) Sobre el culto a la personalidad}

Las críticas a Stalin y el inicio de la «desestalinización», fue uno de los ejes del XX Congreso del PCUS en 1956. El texto base para la discusión fue el «Informe Secreto» de Jruschov, que no formó parte de los in-

14 No obstante, fue antes publicado en el Diario Ostprobleme de Alemania por los servicios secretos de inteligencia norteamericana. Sobre el impacto de la ruptura en las izquierdas, remitimos a AAVV, On Maoism, 1974. 
formes y resoluciones oficiales y que en la URSS sólo fue publicado entero en 1988.

A través de las críticas al modo de dirección personalista llevado a cabo por Joseph Stalin, el PCUS iniciaba un camino de «desestalinización» y de «reivindicación de los métodos leninistas de dirección», centrados en el partido (y no en las personas).

El PCCh inicialmente suscribió a tales críticas reconociendo la audacia del PCUS y deseando que se «liquidaran» los errores cometidos por Stalin $^{15}$. Sin embargo, posteriormente sostendrían que «la crítica de Stalin hecha en el XX Congreso del PCUS fue errónea tanto en los principios como en el método.» ${ }^{16} \mathrm{Y}$ que, bajo el pretexto de combatir abusos de culto a la personalidad, habrían encausado una campaña de persecución e intervención de organismos tanto soviéticos como en el exterior. Enmarcándolo en el conjunto de afirmaciones y cambios con los que polemizaron a partir de entonces, denuncian que las críticas a Stalin fueron en realidad el puntapié para una revisión general de la teoría.

Por el contrario, desde China pasaron a defender la tesis de que Stalin habría cometido «algunos errores graves», pero que «comparados con sus grandes méritos, estos errores son (...) de orden secundario» ${ }^{17}$.Dada la inexistencia de experiencias socialistas previas, algunos errores prácticos habrían sido inevitables. Pero la crítica más fuerte (y origen de sus errores) se debía a problemas gnoseológicos y de concepción filosófica acerca del mundo y su desarrollo. No dimensionar esos aspectos y desechar de conjunto la construcción soviética en los años del stalinismo era, según ellos, ir en contra del marxismo leninismo.

Frente a tales acusaciones y empalmando con una corriente anti-stalinista desde diferentes vertientes, el PCUS respondía que no se trataba simplemente de la apreciación de las actividades de Stalin, sino de extirpar sus métodos ${ }^{18}$. Que el PCCh no podía arrogarse ser el representante y defensor del marxismo-leninismo y «tratar de imponer ese marxismo «propio» a todos» ${ }^{19}$.

15 PCCh, 1957.

16 «El origen y el desarrollo de las divergencias entre la dirección del PCUS y nosotros (sept 1963)», en PCCh, 1965.

17 «Sobre el problema de Stalin. Comentario sobre la carta abierta del CCdel PCUS (II)». Por la Redacción del Renmin Ribao y la Redacción de la revista Hongqi (13 de septiembre de 1963). En PCCh, 1965.

18 PCUS, 1963.a, p. 45.

19 PCUS, 1963 a, p. 48. 


\section{b) Sobre la coexistencia pacífica}

Otro de los puntos de la polémica era aquel acuerdo de «coexistencia pacífica» que habían hecho la URSS y los Estados Unidos. Dado el gran prestigio que tenía el bloque socialista tras la Segunda Guerra y debido a las posibilidades de una nueva guerra nuclear en el contexto de la Guerra Fría, el PCUS afirmaba que «la tarea primordial de los partidos comunistas consiste en cohesionar a todas las fuerzas amantes de la paz para preservar la paz y salvar a la Humanidad de la hecatombe nuclear» ${ }^{20}$. En ese sentido, acordaron con los Estados Unidos un cese del fuego que permitiría, al mismo tiempo, mostrar la superioridad del socialismo en el terreno económico. Así, afirmaban que «la coexistencia pacífica no excluye, sino, al contrario, crea una situación favorable para las transformaciones revolucionarias en la sociedad, no enlentece el proceso revolucionario mundial, sino que contribuye a acelerarle $»^{21}$. El PCCh se opuso a este posicionamiento porque:

(...) significa desorientar a la gente el no distinguir entre los enemigos, los amigos y los propios, y el confiar el destino de los pueblos, el destino de la humanidad, a la colaboración con el imperialismo norteamericano. (...)Hemos considerado siempre que, con el propósito de denunciar y combatir la expansión armamentista y los preparativos bélicos del imperialismo, es necesario plantear la demanda de desarme universal. Por medio de la lucha conjunta de los países del campo socialista y de todos los pueblos del mundo, es posible obligar a los imperialistas a aceptar cierto tipo de acuerdo sobre el desarme.

Si se considera el desarme general y completo como el camino fundamental de la lucha por la paz mundial, si se difunde la ilusión de que el imperialismo puede deponer voluntariamente las armas, y si se anula, so pretexto del desarme, la lucha revolucionaria de los pueblos y naciones oprimidos, esto significa engañar deliberadamente a los pueblos del mundo y ayudar a los imperialistas a aplicar su política de agresión y de guerra. ${ }^{22}$

En las líneas anteriores podemos leer que los chinos acusaban al PCUS de estar confundiendo a los partidos y a la izquierda cuando lla-

\footnotetext{
${ }^{20}$ PCUS, 1963.a, p. 13.

${ }^{21}$ PCUS, 1963.a, p. 27.

22 PCCh, 1965, pp. 16 y 27-28.
} 
maba a confiar en posibles acuerdos de paz con países imperialistas. Por el contrario, proponían que la buena situación del campo socialista debía ser aprovechada para impulsar y apoyar luchas de liberación nacional y social que golpeasen en el corazón del propio imperialismo (de los cuales el peor y más agresivo era el norteamericano) y los obligasen a practicar la paz para con ellos.

\section{c) Sobre la vía para la revolución}

Vinculado al punto anterior, encontramos el debate sobre la posibilidad de la transición pacífica al socialismo, como había afirmado la URSS:

(...) La misión de la clase obrera y de los partidos comunistas consiste en aprovechar al máximo las posibilidades existentes hoy día para seguir la vía pacífica, sin guerra civil, de la revolución socialista y, al mismo tiempo, estar preparados para la vía no pacífica, para aplastar con las armas la resistencia de la burguesía; la lucha democrática general es parte integrante indispensable de la lucha por el socialismo» ${ }^{23}$.

Según ellos, la superioridad del socialismo y la debilidad relativa del imperialismo, permitían pensar en un triunfo sin guerra civil, por lo que orientaban a la lucha parlamentaria como camino para avanzar. Si bien no descartaban la lucha armada, no era tenida como prioritaria. Frente a tal orientación, los chinos rápidamente respondieron que «Los comunistas preferirían siempre realizar la transición al socialismo por vía pacífica. Sin embargo, ¿se puede (...)? No, de ninguna manera.» ${ }^{24} \mathrm{Y}$ agregaron que las revoluciones sociales a lo largo de la historia tenían leyes objetivas, independientes de la voluntad del hombre, descubiertas y desarrolladas por la teoría marxista y que postular la posibilidad de evitarla no sólo sería negarla, sino también desconocer que ninguna revolución socialista había triunfado por ese camino..$^{25}$

Puede resultar paradojal que en la izquierda de los años sesenta (en la cúspide del movimiento socialista) estuviese en debate si la vía para la re-

${ }^{23}$ PCUS, $1963 . \mathrm{a}, \mathrm{p} .13$.

24 PCCh 1965, p. 20.

25 PCCh 1965, p. 20-21. 
volución era armada o parlamentaria. Pero las dos grandes posiciones se basaban en los clásicos del marxismo en sus argumentaciones, sólo que entre ellos se acusaban de «dogmáticos» o «revisionistas».

Siendo el comunismo el fin de la lucha del proletariado, cada país y cada partido político debía analizar la propia situación para formular las tácticas más justas (en términos políticos) en cada momento. ${ }^{26}$ Es sobre este último tema, la valoración del momento político, que existía una fuerte discusión en el MCI: para el PCUS, el PCCh no entendía que el socialismo debía pensar sobre cómo ayudar al triunfo del socialismo del modo «más rápido y menos penoso», eludiendo la real posibilidad de la guerra termo-nuclear con los Estados Unidos, y que «para cumplir su misión histórica, los comunistas tienen que mantener fidelidad inquebrantable al marxismo-leninismo saber aplicar con sentido creador sus principios en la situación histórica concreta.» ${ }^{27}$. E indirectamente hablando de aquéllos, afirman que en las «circunstancias presentes, el dogmatismo, el sectarismo, el aventurerismo y la fraseología revolucionaria están convirtiéndose en un peligro cada día más evidente para el movimiento comunista.» ${ }^{28}$ Para el PCCh, decir que las nuevas condiciones de lucha (inclinadas, en la segunda pos guerra, a favor del campo socialista) permitían pensar en el tránsito pacífico al socialismo, no significaría más que desconocer y traicionar al marxismo-leninismo.

El debate sobre la vía al socialismo estaba colocado y todos los partidos debían tomar posición en relación al mismo.

\section{d) Sobre el «Estado de todo el pueblo»}

A partir del análisis de la situación de la construcción del socialismo en la URSS, los pasos dados desde 1917 y los cambios que habían sucedido en la estructura económico-social del país, el PCUS comenzó a caracterizar al Estado soviético como «Estado de todo el pueblo»:

${ }^{26}$ Fue el mismo Lenin tras la Revolución de Octubre quien criticó el «izquierdismo» de los alemanes al tratar de tomar el poder sin fuerzas revolucionarias. Los orientó a usar el Parlamento y la propaganda como forma de ganar apoyo y adeptos a la causa para, después sí, llevar a cabo la insurrección armada. Lenin, 1958.

27 PCUS, 1963.a, p. 3.

${ }^{28}$ PCUS, 1963.a, p. 9. 
Gracias a la victoria del socialismo en la URSS y la consolidación de la unidad de la sociedad soviética, el Partido Comunista de la clase obrera es hoy el Partido de todo el pueblo (...) Si la sociedad socialista ha alcanzado en su desarrollo una meseta en que se compone de dos clases amigas de trabajadores socialistas — obreros y campesinos - , así como de la intelectualidad popular, las diferencias entre las cuales van borrándose más y más, si todos los grupos sociales, bajo el papel rector de la clase obrera, luchan por construir el comunismo, entonces es completamente natural y lógico que en esta sociedad el Partido Comunista se convierta en exponente y representante de todo el pueblo, en su vanguardia, jefe colectivo y dirigente ${ }^{29}$

Sintetizando las ideas presentes en la fuente, tantos años de socialismo habrían acabado con la explotación del trabajo ajeno y, como consecuencia, las clases sociales existentes (trabajadores - proletarios y campesinos - e intelectuales) ya no serían enemigas entre sí. Por eso, en esa fase de transición al comunismo, el Estado de la dictadura del proletariado se habría transformado en «Estado de todo el pueblo», adecuándose a esa realidad.

Frente a esa caracterización, el PCCh replicó que, según Marx y Lenin, «todo el período anterior a la entrada en la fase superior de la sociedad comunista»y, por lo tanto, de «dictadura del proletariado» (negrita de la autora). Y también que, considerando que para el marxismo-leninismo todo Estado es un Estado de clase, «...tan pronto como la sociedad quede sin clases, dejará de existir el Estado» ${ }^{30}$. En otras palabras, afirman que nunca podría haber un Estado de todo el pueblo, porque sería una contradicción.

Para el PCUS, también citando a Lenin, «la dictadura del proletariado solamente es necesaria en el período de transición del capitalismo al socialismo» y que ésta, como habría señalado Marx, era sólo la primera etapa del comunismo. Y consideraban que era contradictorio por parte de los chinos, la afirmación de que «... en este período de transición la dictadura del proletariado, es decir, el Estado proletario, pasa por un proceso dialéctico de establecimiento, afianzamiento, fortalecimiento y extinción paulatina», porque sería imposible que sucediese, al mismo tiempo, el fortalecimiento y la extinción del Estado ${ }^{31}$. Por otro lado, indi-

\footnotetext{
29 PCUS, 1963. b, pp. 43-44.

30 PCCh, 1965, p. 37.

31 PCUS, 1963.b, pp. 42-43.
} 
caron que Marx y Lenin usaron el concepto «comunismo» para referirse a todo el período posterior al capitalismo. Por ello Lenin habría aclarado en su obra «El Estado y la Revolución», que «a lo que se acostumbra a denominar socialismo, Marx lo llamaba la «primera» fase o la fase inferior de la sociedad comunista. En tanto que los medios de producción se convierten en propiedad común, puede emplearse la palabra «comunismo», siempre y cuando que no se pierda de vista que éste no es el comunismo completo.» ${ }^{32} \mathrm{El}$ período de la dictadura del proletariado, en su interpretación, correspondía apenas a la transición del capitalismo al socialismo. Una vez triunfante, ya no existirían clases enemigas y se iniciaría el período de construcción del comunismo. Los cambios en el Estado sólo eran consecuencia de los cambios en la estructura de clases en la sociedad $^{33}$.

Como consecuencia de todas esas acusaciones, el PCCh acabó acusando al PCUS de revisionista del marxismo-leninismo y este, a su vez, acusaba a los chinos de izquierdistas y nacionalistas. En el fondo, el debate y las acusaciones trascendían la denominación usada. Lo que estaban discutiendo era la existencia o no de clases sociales y sobre la explotación en la URSS. Para el PCCh acabó siendo una de las cuestiones más relevantes de la discusión, porque a partir del análisis acerca de la URSS concluyeron la continuidad de la lucha de clases en el socialismo y, consecuentemente, la posibilidad de restauración capitalista. Las posiciones acerca de la vía para la revolución y las consideraciones sobre la coexistencia pacífica expresarían, al final de cuentas, que la restauración había tenido lugar en aquella parte del globo:

La camarilla revisionista de Jruschov ha renunciado a la dictadura del proletariado bajo la pantalla de «Estado de todo el pueblo», ha alterado el carácter proletario del PCUS bajo la pantalla de «partido de todo el pueblo» y ha abierto el camino a la restauración del capitalismo bajo la pantalla de «edificación del comunismo en todos los frentes ${ }^{34}$.

El salto de la caracterización y de la ruptura fue precipitado por la acusación de «socialimperialistas» del PCCh a su par soviético. Encontrando en la División Internacional del Trabajo Socialista (formulado por

\footnotetext{
${ }^{32}$ Lenin, 2004.

33 PCUS, 1963, p. 41-43.

34 PCCh, 1965, p. 434.
} 
Leónidas Breznhev) y, posteriormente, en la invasión a Checoslovaquia, algunos ejemplos de eso, el PCCh arremetió fuerte contra lo que consideró un gran peligro, sino el mayor (en tanto se presentaba como socialista y amigo de los pueblos pero, en realidad, sería imperialista). ${ }^{35}$

En este trabajo consideramos que fueron estas definiciones en la división del MCI las que dotaron de identidad al maoísmo como corriente diferenciada. Los elementos de la Revolución China vinculados a pensar cómo hacer las revoluciones en los países oprimidos, claramente no pueden ser dejados de lado y fueron muy importantes para entender su influencia en el Tercer Mundo en general, y en América Latina en particular. Más aun, porque fue sobre todo a partir del contexto del debate que la Revolución China ganó relevancia mundial y varias organizaciones estudiaron lo que aquéllos habían hecho hasta el momento.

\section{El debate antes del Cisma: las Conferencias Mundiales de 1957 y 1960}

Destacamos que, aunque las diferencias hubiesen comenzado después del XX Congreso del PCUS en 1956, el debate transcurrió centralmente por canales privados y que el contenido de los intercambios sólo se hizo público una vez producida la ruptura. De un comienzo signado por evasivas y generalidades, el tono y las acusaciones se irán tornando más directas y agudas. Por ello partimos por el final, para abordar ahora aspectos de gestación y desarrollo.

Es preciso tener presente que tras la disolución del Kominform en 1956, había desaparecido todo organismo formal permanente en el MCI. Sin embargo, las revueltas polaca y húngara de aquel año, reclamaron que hubiese una instancia de debate y una posición unificadas al respecto. En ese contexto surgieron las Conferencias Mundiales ${ }^{36}$, que se convirtieron en el espacio privilegiado para articular las diferentes posiciones que ya habían emergido. El objetivo de tales instancias era discutir e intercambiar acerca del balance, el análisis de la situación y las tareas que debían darse.

${ }^{35}$ La constante crítica a la URSS no fue bien recibida por otras fuerzas políticas que acusan a los maoístas de haber perdido de vista al verdadero enemigo.

${ }^{36}$ Las Conferencias diferenciaban a los Partidos Comunistas de países socialistas de aquellos partidos comunistas y obreros en donde aún no habían hecho la revolución. Los lineamientos generales y conflictos del mundo socialista eran discutidos solo entre los primeros. Para las Declaraciones y Manifiestos, esos últimos sí eran incluidos. 
En el lapso del Debate se realizaron dos Conferencias (1957 y 1960) en las que confiaron haber llegado a acuerdos. Cobran especial relevancia en nuestro trabajo, puesto que en los documentos aprobados es posible identificar las disputas acerca de las formulaciones que acabaría adoptando el conjunto de Partidos Comunistas. Según Lily Marcou ${ }^{37}$, «las fórmulas de compromiso» fueron el verdadero sentido de las «Conferencias». Como proponemos a continuación, en el análisis de los documentos elaborados es posible leer la tensión y los debates que atravesaba el MCI, y cómo el maoísmo se fue configurando como una corriente alternativa dentro del mismo.

\section{La Conferencia de $1957^{38}$}

La misma fue realizada en Moscú en noviembre de 1957 y fue protagonizada por los partidos comunistas de 12 países socialistas ${ }^{39}$. El resultado de tal evento fueron una declaración aprobada unánimemente (y consultado con los «partidos fraternos de los países capitalistas») y un «Manifiesto por la paz», elaborado por los partidos comunistas y obreros de todo el mundo.

La «Declaración de los 12», como se la ha conocido, es un texto dividido en cuatro secciones.

La primera parte trata acerca de la caracterización del mundo y la situación de ese momento. La misma, que estaría marcada por «la marcha y los resultados de emulación entre dos sistemas sociales opuestos» ${ }^{40}$, exigiría la lucha por la paz, colocándola como «Tarea Primordial» ${ }^{41}$. En efecto, se evalúa que «la cuestión guerra o coexistencia pacífica es hoy el problema clave de la política mundial [negrita autora] $\gg^{42}$, puesto que el socialismo, que ya había triunfado en más de una tercera parte de la población de la Tierra, estaría en condiciones de demostrar su superioridad material

37 Marcou, 1981.

38 AAVV, «El contenido ..., 1961

39 Partido del Trabajo de Albania, Partido Comunista Bulgaria, Partido Socialista Obrero de Hungría, Partido de los Trabajadores del Viet-Nam, Partido Socialista Unificado de Alemania, Partido Comunista de China, Partido del Trabajo de Corea, Partido Popular Revolucionario de Mongolia, Partido Obrero Unificado de Polonia, Partido Obrero de Rumania, Partido Comunista de la Unión Soviética, Partido Comunista Checoslovaquia.

40 AAVV, «El contenido..., 1961, p. 146.

41 AAVV, «El contenido..., 1961, p. 149.

42 AAVV, «El contenido..., 1961, p. 148. 
y moral. La Guerra sólo podría traer penurias para los pueblos, y los socialistas tenían el deber de batallar contra ese peligro.

Si la primera sección estaba orientada a sentar posiciones acerca de la tarea central en donde la URSS habría conseguido imponer su valoración, la segunda, aunque más corta, cambiaba totalmente el eje para dejar asentado el tipo de vínculos que debía entablarse entre los Estados Socialistas: estos debían estar basados en la «plena igualdad, independencia estatal y la soberanía y la no injerencia en los asuntos internos $»^{43}$. Aparece aquí lo que identificamos como una de las reivindicaciones del PCCh, que cuestionaba tanto en forma como en contenido la política llevada a cabo por el PCUS hacia el resto de los PCs dentro del MCI.

Ya en la tercera parte, las aseveraciones giran en torno al balance acerca de los problemas y desafíos que atañen al Movimiento Comunista en su interior. Es llamativa la redacción y, conociendo los debates que se desarrollaban, es posible leerlos en las formulaciones. Si luego de afirmar que el Marxismo-Leninismo había demostrado su justeza a partir de demostrar «que los procesos de revolución y edificación del socialismo se basan en leyes fundamentales ${ }^{44}$, se incorpora que tales leyes permitirían combinarse con las condiciones particulares. «En la etapa actual», sería muy importante luchar contra el «revisionismo» y el «dogmatismo» ${ }^{45}$. Tras esa afirmación, encontramos un primer abordaje y fuerte crítica al dogmatismo y sectarismo, seguido de que «el peligro principal al momento es el revisionismo [cursiva de la autora]». Llamativamente, a continuación es matizada al sostener que «sin embargo, el dogmatismo y el sectarismo pueden constituir el peligro principal en distintas etapas del desarrollo de uno u otro partido. Cada partido determina qué peligro es para él el mayor en cada momento dado» ${ }^{46}$.

Como puede apreciarse, cada oración expresa los aspectos del debate que quería resaltar cada parte (los chinos acusando de revisionistas y de imponer su visión a la URSS, y el PCUS tratado de marginalizar la experiencia china para evitar que se vuelvan línea política y de criticarles su rigidez conceptual). Inclusive las afirmaciones generales son inmediatamente matizadas o relativizadas en un posible contexto diferente. PCCh.

43 AAVV, «El contenido..., 1961, p. 150.

${ }_{44}$ Cuyo listado se enumera en AAVV, «El contenido..., 1961, p. 152.

45 Recordemos que esos serán los términos bajos los cuales se acusaban el PCUS y el

46 AAVV, «El contenido..., 1961, p. 154. 
La última sección retoma las «tareas históricas» [la revolución y el tránsito al socialismo] que aún tiene por delante la mayoría de los partidos y países. Sostiene que

«Las formas del tránsito del capitalismo al socialismo pueden ser diversas y que La clase obrera y el partido M-L tienden a hacerla por vía pacífica (...) En las condiciones actuales, en varios países es posible con conquistar el poder estatal sin guerra civil (...) En caso de que las clases explotadoras recurran a la violencia en contra del pueblo, hay que tener presente otra posibilidad: el paso al socialismo por vía no pacífica. En cada país, (...) viene determinada por condiciones históricas concretas.» ${ }^{47}$

Aquí otro aspecto (el de la vía pacífica o armada) aparece formulado en los mismos términos que el recientemente abordado: su redacción posibilita aferrarse a una u otra parte de lo asentado.

Finalmente, cabe reparar en que en el cierre del documento se reafirma la misión de luchar lo más amplia y conjuntamente por lo que serían los fines comunes: la paz, la democracia y el socialismo ${ }^{48}$.

El «Manifiesto por la Paz» firmado por los partidos comunistas y obreros de 61 países se desprende de la Declaración, sólo que se atiene a los puntos I y IV desarrollados anteriormente.

\section{La Declaración de 1960}

La «Declaración de la Conferencia de Representantes de los partidos comunistas y obreros», conocida posteriormente como «Declaración de los 81», es un texto fundamental en el proceso que abordamos. Por un lado, porque se trata de un documento que ratifica los acuerdos de 1957 y los despliega en una argumentación mucho más extensa y detallada. Por otro, porque en el marco de los fuertes debates que trascurrían y que cada vez cobraban mayor peso, se convirtió en un instrumento a través del cual se posicionaron los PCs del mundo entero. ${ }^{49}$

47 AAVV, «El contenido..., 1961, pp. 156-157.

48 AAVV, «El contenido..., 1961, p. 159.

49 En Argentina, por ejemplo, es elevada dentro del PC a la categoría de «Documento histórico» (Nuestra Palabra 24/1/61, pag. 2) Cuando se publica a modo de libro junto con otros textos (versión que utilizamos), es este último el escogido para encabezar la compilación. Desde una perspectiva más general, Robert Alexander cita en su trabajo un informe de 
De ese modo, en el acápite I encontramos las afirmaciones de que «[en la época actual] el principal rasgo es que el socialismo se va convirtiendo en factor decisivo del desarrollo de la sociedad humana [cursiva en el original]», pero que al capitalismo se lo derrotará «en la esfera decisiva de la actividad humana: en la esfera de la producción material» ${ }^{50}$. El retroceso del sistema capitalista y el avance del socialismo, devendría en una intensificación de la lucha interimperialista por las áreas de control ${ }^{51}$, aunque el rasgo central de la etapa lo constituiría no la guerra, sino «la emulación y lucha entre dos sistemas» ${ }^{52}$.

Ya el II acápite avanza en la caracterización del mundo socialista y, específicamente, en los desarrollos alcanzados en la Unión Soviética, que llevaría a cabo «con éxito la construcción de la sociedad comunista en todos los frentes [cursiva en el original] $»^{53}$. Ello simplemente querría significar lo que a continuación se explicita: «En el presente no sólo en la Unión Soviética, sino también en los demás países socialistas, han sido liquidadas las posibilidades económico sociales de restauración del capitalismo [cursiva en el original] $\gg^{54}$.

Nótese el énfasis y la precisión de los términos escogidos, en clara dirección a las acusaciones que recibían de sus pares chinos. Al mismo tiempo, se insiste en que «Todos los países socialistas cuidan, como de las niñas de los ojos, de la unidad del campo socialista ${ }^{55}$. Las relaciones, se repite varias veces, deben basarse en el internacionalismo proletario. Pero atiéndase el siguiente extracto acerca de lo general, lo particular y los vínculos entre Estados:

«en la declaración de 1957 se señala con toda razón que la exageración del papel de las peculiaridades nacionales, el abandono de las tesis generales del marxismo-leninismo acerca de la revolución socialista y de la edificación socialista, son perjudiciales a la causa general del socialismo. Al mismo tiempo, la Declaración señala también con toda justeza que el marxismo leninismo exige la aplicación creadora de los

\footnotetext{
Inteligencia del gobierno estadounidense de 1969, en el cual se analizan los apoyos de los diferentes partidos comunistas del mundo para con la URSS y China. Alexander, 1999, p. 20.

50 AAVV, «Declaración...», 1961, p. 10.

51 AAVV, «Declaración...», 1961, p. 14.

52 AAVV, «Declaración...», 1961, p. 18.

53 AAVV, «Declaración...», 1961, pp. 18-19.

54 AAVV, «Declaración...», 1961, p. 23.

55 AAVV, «Declaración...», 1961, p. 24.
} 
principios generales de la revolución socialista y de la edificación del socialismo en relación con las condiciones históricas concretas de cada país y no tolera la copia mecánica de la política y de la táctica de los partidos comunistas de otros países. El hacer caso omiso de las peculiaridades nacionales puede llevar al partido proletario a divorciarse de la vida, de las masas, a inferir daño a la causa del socialismo». ${ }^{56}$

Si la primera parte pareciera ser una crítica de la URSS al PCCh, la siguiente frase encabezada por «al mismo tiempo», pareciera ser el resultado de una formulación propuesta por los chinos.

Es importante reparar en que las acusaciones no son frontales y directas. Su lectura es posibilitada por el conocimiento de las cartas intercambiadas (publicadas posteriormente) y por conocer el desenlace de tales discrepancias.

Evidentemente, alguna de las partes de tal reunión consideró menester dejar explicitado en el apartado III (acerca de la coexistencia pacífica) que la misma «no significa, como afirman los revisionistas, la renuncia a la lucha de clases [cursiva de la autora]» ${ }^{57}$ ni «la conciliación de la ideología socialista con la burguesa» ${ }^{58}$. Aquí cabe la pregunta de si el contenido fundamental era la aclaración o el dejar asentada la denuncia.

Los apartados subsiguientes se posicionan acerca de la lucha por la democracia como parte constitutiva de la lucha por el socialismo. En ella aparecen tesis acerca de la burguesía nacional y su rol, que en determinadas condiciones vendrían a facilitar la posibilidad de tránsito pacífico al socialismo ${ }^{59}$.

El cierre se pronuncia fuertemente por la unidad del MCI, que involucra a PC de 87 países y reúne a más de 36 millones de personas ${ }^{60}$, alerta nuevamente contra a el revisionismo y dogmatismo ${ }^{61}$, critica el camino de Yugoslavia ${ }^{62}$ y, si bien reconoce la igualdad entre los partidos, se «declara unánime que la vanguardia ha sido y seguirá siendo el PCUS (...)», cuyo «XX congreso dio comienzo a nueva etapa en el MCI.»63

56 AAVV, «Declaración...», 1961, p. 28.

57 AAVV, «Declaración...», 1961, p. 41.

58 AAVV, «Declaración...», 1961, p. 42.

59 AAVV, «Declaración...», 1961, pp. 50-64. En este artículo no profundizaremos sobre las consecuencias de tales concepciones para los PCs de América Latina.

60 AAVV, «Declaración...», 1961, p. 67.

61 AAVV, «Declaración...», 1961, p. 70.

62 AAVV, «Declaración...», 1961, p. 69.

63 AAVV, «Declaración...», 1961, p. 73. 
Como anticipamos al inicio de este apartado, las formulaciones acabaron siendo bien amplias y generales para contemplar las diferencias e incluir a todos. Cada Partido leyó las conclusiones del modo en que mejor lo favorecía. Así, el PCUS acusaría

«Sin molestarse en hacer un análisis científico de la situación actual, cautivos de las frases generales y citas, los camaradas chinos, desde las posiciones del oportunismo izquierdista y nacionalista, someten a completa revisión los documentos programáticos del movimiento comunista mundial en todos los problemas fundamentales: carácter de la época actual y su principal contradicción, papel del sistema socialista mundial, problema de la guerra y la paz, desarrollo del proceso revolucionario y formas de tránsito al socialismo, movimiento de liberación nacional, experiencia internacional en la edificación del socialismo, principios de las relaciones entre los partidos comunistas; lucha contra el culto a la personalidad y otros. $\rangle^{64}$

Y, por su parte, el PCCh se vanagloriaba de su rol activo en evitar que las tesis revisionistas prosperaran en ambas Declaraciones ${ }^{65}$, a pesar de lo que el PCUS se habría encargado de «atropellarlas» en menos de veinticuatro horas. ${ }^{66}$

Las divergencias se transformaron en un franco enfrentamiento y disputa por el liderazgo del MCI.

\section{A modo de cierre}

En este trabajo hemos procurado documentar y analizar la emergencia del maoísmo como corriente diferenciada dentro del MCI.

Dada la rápida asimilación que se produce entre las características del proceso de la Revolución China y el maoísmo, en este artículo hemos propuesto una forma de abordaje que, si bien parte de contemplar al conjunto de los elementos, los diferencia en función de su significado en lo que se ha denominado maoísmo y que innegablemente, hizo su aparición pública en la década de 1960.

\footnotetext{
${ }^{64}$ PCUS, $1963 . \mathrm{a}, \mathrm{p} .7$.

65 PCCh, 1965, pp. 86, 90 y 91.

66 PCCh, 1965, p. 95
} 
En el trabajo sostuvimos que si bien desde el triunfo mismo de la revolución la experiencia china fue inspiradora de otros movimientos revolucionarios, solo a partir del cisma chino-soviético se puede hablar de maoísmo y que el período 1956-1963 fue clave en la gestación de tal corriente de manera diferenciada. El punto de partida estaría dado por la realización del XX Congreso del PCUS y la fecha que tomamos por cierre, responde a la ruptura definitiva de relaciones entre ambos partidos.

En ese período se fueron delineando los ejes en torno a los cuales confrontarían los dos modos de valorar la etapa mundial y las tareas que el socialismo tenía por delante. Si el debate sobre el culto a la personalidad (centrado en la figura de Stalin) abrió un camino de críticas y autocríticas, fueron centralmente la valoración sobre el momento político internacional (y la viabilidad o no de la coexistencia pacífica) y la vía armada o pacífica para la toma del poder los que tensaron la confrontación. Conforme iba avanzando la polémica, la caracterización del Estado existente en la URSS iba cobrando relevancia. Su reconocimiento o no como «Estado de todo el pueblo», se entrelazaba crecientemente con la posición acerca de la existencia o no de clases sociales y lucha de clases en el socialismo. Esto último acabó aseverando Mao Tse Tung y sería reconocido como el «aporte» fundamental al marxismo-leninismo, según quienes se inscribieron en dicha corriente.

Con respecto al culto a la personalidad y la forma concreta que asumió (la valoración de Stalin), el maoísmo se relacionó de una manera contradictoria. Contextualizándolo históricamente, lo considera como un momento «necesario» del desarrollo del socialismo, pero le critica profundamente sus concepciones políticas y teóricas. Su foco estuvo puesto en evitar que las críticas a Stalin y el stalinismo devinieran en lo que denominaron el revisionismo en el que habría caído la URSS. Tal peligro, era considerado por ellos mucho peor para la lucha revolucionaria.

Mientras el debate discurrió internamente, se realizaron dos Conferencias Mundiales (1957 y 1960) atravesadas por esta coyuntura. Hemos ofrecido una lectura de las mismas en la que es posible entrever los debates que se hicieron públicos posteriormente y cómo aparecen como un momento clave en la consolidación de la corriente maoísta.

El Partido Comunista Chino, en una clara inferioridad en su influencia, buscó dejar asentadas sus posiciones y sus críticas, diferenciándose crecientemente del Partido Comunista de la Unión Soviética. De allí que la defensa de la vía armada para la revolución, la imposibilidad de la coexistencia pacífica con el bloque capitalista hegemonizado por los Esta- 
dos Unidos y la continuidad de la lucha de clases fueran los ejes que acabaron diferenciándolo de su par soviético. Más aún, el triunfo de la otra línea en dicho territorio, no sería más que la comprobación de la restauración capitalista en la URSS.

A partir de la ruptura en el MCI comenzaron a conformarse los partidos marxistas-leninistas-maoístas (que debían suscribir a estos postulados). A su vez, la confrontación con el PCUS y sus métodos burocráticos de dirección hizo que sedujera también a numerosas personalidades y contingentes del mundo que confluyeron en la crítica a la transición pacífica (en América Latina más aún tras el triunfo cubano de 1959).

$\mathrm{Al}$ respecto, Michael Lowy ${ }^{67}$ inscribe al maoísmo europeo (occidental) dentro de una corriente «romántico revolucionaria» de la época, caracterizado por una fuerte crítica al mundo industrial y mecanizado y en donde se denunciaba una «pérdida de los valores cualitativos» que habría seducido a muchos intelectuales diversos como Georg Lukács, Walter Benjamin, Theodor Adorno, Herbert Marcuse o Henri Lefebvre. Miguel Cardina ${ }^{68}$, en su estudio para el maoísmo portugués, sostiene que primero el debate con la URSS (centro incuestionable hasta entonces) y luego el cuestionamiento a las jerarquías que era alentado en la Revolución Cultural, empalmaron con diversos sectores que se vieron atraídos por esta novedosa «crítica» dentro de la izquierda. En ella habrían confluido anarquistas, leninistas y «espontaneístas». En el mismo sentido, Jean Sales ${ }^{69}$ propone para el caso brasilero que muchos jóvenes se vieron seducidos por el maoísmo en su etapa de la Revolución Cultural, por «la ruptura con muchos dogmas de la organización en los moldes de los partidos comunistas, una ruptura con las estructuras del funcionamiento dela sociedad, con un fuerte componente «libertario»» ${ }^{70}$. A partir de la Revolución cultural, pareciera haber un nuevo afluente hacia el maoísmo: a aquél con una fuerte impronta de la ortodoxia leninista (que se remontaban al debate con las URSS), se agregaba uno de cariz romántica, casi voluntarista.

Estas interpretaciones y las diferentes vertientes nos permiten entender por qué fue posible que confluyesen en el maoismo expresiones tan disímiles como los intelectuales franceses de 1968 o grupos armados guevaristas latinoamericanos.

\footnotetext{
67 Lowy, 2002.

68 Cardina, 2011.

69 Sales Rodriguez, 2000.

70 Sales, 2000, p. 108.
} 
Con base en la defensa de la vía armada como única posible para la toma del poder, la crítica a la posibilidad de la coexistencia pacífica con el bloque capitalista en el marco de la Guerra Fría y la elaboración de la teoría de la lucha de clases en el socialismo, emergió dentro del Movimiento Comunista Internacional en 1960 la corriente que podemos denominar maoísta.

Retomando el planteo del inicio, el maoísmo emerge como un momento específico dentro de la Revolución China y se gestó en oposición al liderazgo de la URSS dentro del Movimiento Comunista Internacional, con una política creciente de búsqueda de reconocimiento y disputa.

\section{Fuentes}

AAVV, Hacia Nuevas victorias del movimiento comunista mundial. Buenos Aires, Ed Anteo, 1961. Contiene: «El contenido fundamental de nuestra época es el paso del capitalismo al socialismo», «Manifiesto por la paz. Los partidos comunistas y obreros a todos los pueblos del mundo.», «Declaración de la Conferencia de Representantes de los partidos comunistas y obreros».

AAVV, On Maoism. Excerpts from official Documents, statements by leaders of Marxist-Leninist parties, and articles published in the Communist Press concerning Peking's Great-Power Polley (1969-1973) Moscow, Novosti Press Agency Publishing House, 1974

PCCH, Polémica acerca de la línea general del Movimiento Comunista Internacional, Ediciones Lenguas Extranjeras, Pekín 1965. Digitalización realizada por el Partido Comunista Revolucionario del Uruguay. Accesible en https:// www.marxists.org/espanol/tematica/china/documentos/pol.pdf

$\mathrm{PCCH}$, Una vez más sobre la experiencia histórica de la dictadura del proletariado [versión española del artículo publicado por el periódico chino Jenminziphao el 29 de diciembre de 1956], Buenos Aires, Ed.Anteo, 1957.

PCUS, «Por el triunfo del marxismo-leninismo creador. Contra la revisión del rumbo del Movimiento Comunista Mundial», revista Kornmunist n.$^{\circ} 11$, 1963.a.

PCUS, «Carta Abierta a las Organizaciones Partidarias, a Todos los Comunistas de la Unión Soviética». Comité Central del Partido Comunista de la Unión Soviética 14 de julio de 1963.b

Nuestra Palabra (periódico del Partido Comunista Argentino) 24/1/61 . 
El debate chino-soviético y la emergencia del maoísmo como corriente...

\section{Referencias bibliográficas}

AAVV, Maoism Unmasked, Collection of Soviet Press Articles, Progress Publishers Moscow, 1972.

AAVV, Pekín y Moscú, Buenos Aires, Jorge Álvarez Editores, 1964.

AleXANDER, Robert International Maoism in the Developing World. Paeger. London. 1999.

Alexander, Robert. Maoism in the Developed World. Praeger. London, 2001.

ARCHILA, Mauricio. «El maoísmo en Colombia: la enfermedad juvenil del marxismo-leninismo». En Controversia, n. ${ }^{\circ}$ 190, 2008. pp 148-197.

Cardina, Miguel, Margem de certa maneira. O maósmo em Portugal 19641974, Lisboa, Tinta da China, 2011.

CoHEN, Arthur, «How original is maoism?» En Problems of Communism vol. X, n. ${ }^{\circ} 6$ (nov-dez 1961), 34-42. Republicado en StanKIEWICK, W. (ed.), Political Thought since World War II. Critical and interpretative Essays. NY, The Free Press, 1964.

DeUTSCHER, Isaac. El maoísmo: Orígenes y perspectivas. The Socialist Register y Les Temps Modernes, 1964.

LENIN, Vladimir, El Estado y la Revolución, Buenos Aires, 2004.

LENIN, Vladimir, La enfermedad infantil del izquierdismo en el comunismo, en Obras completas, Buenos Aires, Cartago, 1958.

Lowy, Michael, «The revolutionary romanticism of May 1968», en Thesis Eleven, . $^{\circ} 68$, pp. 95-100.

Mao Tse Tung „«Sobre la Nueva Democracia» (enero de 1940), Obras Escogidas de Mao Tse-tung, Tomo II, Pekín, Ediciones en Lenguas Extranjeras, 1976.

Mao Tse Tung, «Problemas de la guerra y de la estrategia» (6 /11/ 1938), Obras, tomo 8, Buenos Aires, Ed de la Paloma, 1974.

Mao Tse Tung, «La revolución China y el PCCh (dic de 1939)», Obras, tomo 5, Buenos Aires, Ed La Paloma, 1973.

Marcou, Lily, El movimiento comunista internacional desde 1945, Madrid, Siglo XXI, 1981.

MEISNER, Maurice, «Marxismo, maoísmo, y la revolución china: Un comentario sobre el papel de las ideas en la historia» en Herramienta , n. ${ }^{\circ} 37$, marzo 2008.

Pons, Silvio. A revolução global: história do comunismo internacional, 19171991. Rio de Janeiro, Contraponto Editora; Brasília, Fundação Astrojildo Pereira, 2014.

Rodrigues SAles, Jean. O Partido Comunista do Brasil-PCdoB: propostas teóricas e práticas política- 1962:1976. Dissertação de Mestrado. Campinas, SP, 2000.

Rothwell, Matthew. Transpacific Revolutionaries: The Chinese Revolution in Latin America. New York, Routledge, 2013. 
Rothwell, Matthew, «Influencia de la revolución china en América Latina: México, Perú y Bolivia». En: Rev. Fuent. Cong. [online]. vol. 4, n. ${ }^{\circ} 9$, 2010, pp. 5-11. Disponible en: www.revistasbolivianas.org.bo/scielo. php?script=sci_arttext\&pid=S1997-44852010000400003\&lng=pt\&nrm=iso

RUPAR, Brenda, «Los desafíos en la investigación histórica sobre corrientes políticas: algunas reflexiones a partir del estudio del maoísmo en Argentina», en Brenda Rupar, Ana Costilla y Guido Galafassi (comp.), Dirán «hubo gigantes aquí»: Izquierda, peronismo y clase obrera en los '60 y '70, Ranelagh, Ed. Extramuros, 2017.a. ISBN 978-987-22408-3-7

RUPAR, Brenda, «El rol de la Revolución Cultural China en el maoísmo argentino. Las interpretaciones en las visiones oficiales de Vanguardia Comunista y el Partido Comunista Revolucionario» Leste Vermelho. Revista de Estudos Críticos Asiáticos. Vol 3, N. . 1, 2017.b, pp. 355-375.

Toledo Bruckmann, Ernesto, «El pensamiento Mao Tse Tung en el Perú. Orígenes y división en la izquierda peruana en 1964». Consultado en http://www. pcdelp.patriaroja.org.pe/el-pensamiento-mao-tse-tung-en-el-peru-origenesy-division-en-la-izquierda-peruana-en-1964-parte-1/

URREGO, Miguel Ángel, «Historia del maoísmo en América Latina: entre la lucha armada y servir al pueblo», Anuario Colombiano de Historia Social y de la Cultura, n. ${ }^{\circ} 44.2,2017$, pp. 111-135.

El presente trabajo forma parte de mi investigación doctoral acerca de la emergencia del maoísmo como corriente política en Argentina. Su abordaje se hizo necesario sobre la base de la inexistencia de bibliografía académica en español que abordara tal problemática. Agradezco el intercambio y los comentarios de colegas y evaluadores en las diferentes instancias de intercambio. A su vez, los desligo de toda responsabilidad por lo escrito.

\section{Datos de la autora}

Benda Rupar (brendarupar@yahoo.com). Argentina, Doctoranda en Historia en la Facultad de Filosofía y Letras de la Universidad de Buenos Aires (UBA), con beca Interna Doctoral del Consejo Nacional Investigaciones Científicas y Técnicas (CONICET). Mestre em História por la Universidade Federal Fluminense (UFF), Brasil.

Investiga cuestiones referentes a Historia de las Izquierdas en Argentina y América Latina. Ha publicado artículos en revistas especializadas, en libros y participado (como coordinadora y como ponente) en varios eventos científicos.

Integrante del Grupo de Estudios sobre Acumulación, Conflicto y Hegemonía (GEACH) y del Centro de Investigaciones sobre Economía y Sociedad en la Argentina Contemporánea (IESAC), ambos radicados en la UNO. 